\title{
CONFERENCE STATEMENT
}

The Conference Statement was negotiated by the Organizing and Programme Committees, the Session Chairs, and representatives of sponsors, based on input from the broad community during and after the conference.

\section{VISION}

Provision of routine and sustained global information on the marine environment sufficient to meet society's needs for describing, understanding and forecasting marine variability (including physical, biogeochemical, ecosystems and living marine resources), weather, seasonal to decadal climate variability, climate change, sustainable management of living marine resources, and assessment of longer term trends

In order to serve the needs of our nations and of the global community, We, the more than $\mathbf{6 0 0}$ Participants from 36 nations of the OceanObs'09 Conference in Venice,

Recognizing the progress in ocean observations in the last decade, the demonstrated societal benefits of the existing elements, the recent technical and scientific developments that enable enhancements to observing systems and ensuing services,

Having broadly consulted with the communities involved in the production, distribution and use of ocean information,

Informed by 99 Community White Papers, 47 Plenary Papers, and discussions captured in the Conference Summary,

Call for significantly enhancing internationallycoordinated provision of sustained observation and information of the world ocean, as a part of the larger earth system observing effort, for public good and stewardship.

Core principles of participation in the sustained observing system include recognition that users require rapid access to all relevant data, free of charge. An integrated system, making use of remotely sensed and in-situ observations is essential. Observations are openly shared in near-real-time when technically feasible. They are collected, analyzed, archived, and distributed to internationally agreed standards with agreed best practices.

Despite the profound importance of marine information to meet the needs of our societies, the resources necessary to observe, assess and forecast global marine conditions are fragile and insufficient.

A true global partnership with strong local benefits requires involvement of all stakeholders. All nations must work together for mutual benefit, through educational programs and development of national capacity.
Many organizations are playing roles to sustain and develop the ocean observing system.

At the global level, the Intergovernmental Oceanographic Commission of UNESCO (IOC), the World Meteorological Organization (WMO), the UN Environment Program (UNEP) and the International Council for Science (ICSU) sponsor the Global Climate Observing System (GCOS), the Global Ocean Observing System (GOOS) and the World Climate Research Program (WCRP), which have taken the lead in formulating the present plan for the sustained global ocean observing system. The satellite agencies of the world also play a fundamental role in the integrated observing system, and the Committee on Earth Observation Satellites (CEOS) has helped coordinate a global response to needs. Nations have been urged to act on this GCOS Implementation Plan by the UN Framework Convention on Climate Change (UNFCCC) and the Group on Earth Observations (GEO). The WMO-IOC Joint Technical Commission for Oceanography and Marine Meteorology (JCOMM) and its partner global observing networks coordinate observations, standards, the data system, and the development of services for much of the physical and carbon ocean observing system. ICSU's Scientific Committee on Oceanic Research (SCOR) coordinates international ocean research that has and will develop observing techniques and networks that become a part of the sustained ocean observing system. The Scientific Committee on Antarctic Research (SCAR) facilitates and coordinates research in the Antarctic and Southern Ocean. The Partnership for Observation of the Global Oceans (POGO), a forum for leaders of major oceanographic institutions responsible for implementation and operation of various observing elements, advocates integrated global ocean observing systems and helps build the capacity to make them a reality. The International Council for the Exploration of the Sea (ICES) is committed to a strengthened role for scientific research on marine ecosystems as a basis for advice that is unbiased, sound, reliable, and credible, to the benefit of management and conservation of marine ecosystems and living marine resources. The North Pacific Marine Science Organization (PICES) coordinates scientific research and observations on marine environment, ecosystems, and their living resources in the North Pacific and its marginal seas. The Census of Marine Life (CoML) is global network to assess and explain the diversity, distribution, and abundance of life in the oceans. The International 
Geosphere-Biosphere Programme (IGBP) and its marine projects promote the development of ocean observing techniques and provide research results that will become a growing part of a global integrated ocean observing system.

At the regional and national level, meteorological agencies, oceanographic agencies, space agencies, fisheries agencies, research funding agencies, marine research institutions, ocean-related service providers, regional alliances, and the Large Marine Ecosystem (LME) program are all key contributors to a sustained ocean observing and information system.

The ocean observing system must be sustained and enhanced:

BECAUSE systematic observation of the properties of the ocean and the information derived are changing what we know about the ocean and its implications for society,

BECAUSE the real-time flow of these observations underpin the development, production, and delivery of many ocean services and support coastal zone management,

BECAUSE global ocean information is critical to support forecasting of climate, weather and natural hazards from daily to centennial time scales,

BECAUSE the development of an increasing range of ocean assessments and climate services for planning, early warning, adaptation and mitigation, depend upon availability of accurate observations and models of the world ocean,

BECAUSE the ocean is an important sink of anthropogenic $\mathrm{CO} 2$, and ocean acidification potentially has significant impacts on marine ecosystems

BECAUSE sustainable management of marine living resources depends on timely and accurate monitoring of and information on biogeochemical cycles and ecosystem function,

BECAUSE biodiversity is understood to be a key factor in ensuring sustainable ecosystem function,

BECAUSE healthy coastal environments and their interactions with the open ocean are important to society, and

BECAUSE the oceans remain seriously undersampled, and no single nation can perform all necessary ocean observations
In solidarity, the Conference:

(1) Calls on all nations and governments to fully implement by 2015 the initial physical and carbon global ocean observing system originally envisioned at OceanObs'99, and refined at OceanObs'09.

(2) Calls on all nations and governments to commit to the implementation and international coordination of systematic global biogeochemical and biological observations, guided by the outcomes of OceanObs'09, and taking into account regional variations in ecosystems.

(3) Invites governments and organizations to embrace a framework for planning and moving forward with an enhanced global sustained ocean observing system over the next decade, integrating new physical, biogeochemical, and biological observations while sustaining present observations. Recommendations on this Framework, considering how to best take advantage of existing structures, will be developed by an postConference working group of limited duration.

(4) Urges the ocean observing community to increase our efforts to achieve the needed level of timely data access, sensor readiness and standards, best practices, data management, uncertainty estimates, and integrated data set availability.

(5) Asks governments, organizations, and the ocean observing community to increase their efforts in capacity-building and education. 